\title{
GEN MZ TOWARD SUSTAINABLE FASHION PRACTICES - ALTERNATIVE SERVICES AND BUSINESS MODELS
}

\author{
Alma Leora Culén and Swati Srivastava \\ Department of Informatics, University of Oslo \\ P. Boks 1080, 0316 Blindern, Oslo, Norway
}

\begin{abstract}
As information emerges on the scale and seriousness of environmental, economic, and socio-cultural challenges related to the fashion industry, millennials and Generation Z (Gen MZ) consumers direct their attention to sustainable fashion. Their perspective and possible influence on the future of more responsible consumption is not fully explored, especially in terms of 1) understanding of the complexities of industry's unsustainability, 2) what it implies concerning sustainable fashion consumption, and 3) using the opportunities that ICT provides to create platforms, services, and business models that align with their visions, demands, and needs. This paper describes two small qualitative studies tackling these gaps - an action research intervention and an open questionnaire, both focusing on already sustainability-aware consumers, to gain insights about their thoughts on sustainable fashion, including acquisition and dispossession decisions, the importance of understanding production challenges, awareness/action gap, and their visions in terms of novel services and business models. Using transition design framework, and in conjunction with our previous work, findings served to envision local, community-based alternative services and business models that support more responsible consumption and continued, dynamic creation of sustainable fashion practices among Gen MZ consumers.
\end{abstract}

\section{KEYWORDS}

Sustainable Fashion, Green Choices, Responsible Consumption, Transition Design, Service Design, Gen MZ

\section{INTRODUCTION}

Growing awareness of the heavy environmental impact of the fashion industry led to particular urgency in rethinking the industry's unsustainable practices, business models, and opacity regarding its life cycle stages. The latter has been perceived as an essential barrier for consumers, retailers, and designers in understanding life cycle processes and their negative impact on the environment (Environmental indicator report, 2014). Every stage of the fashion life cycle (growing plants to extract fibers/artificial fiber production, manufacturing, distribution, use, and disposal) has a high environmental impact. The European Environmental Agency (ibid.) ranked the industry fourth by negative environmental impact. Despite recognition of the above challenges, we are witnessing a substantial increase in fashion consumption. This increase is linked, at least partially, to the success of the fast fashion business model, which promotes inexpensive and trendy clothing with a short lifespan manufactured in developing countries under unfavorable or unethical conditions (Niinimäki et al., 2020). Ellen MacArthur Foundation reports that hundreds of billions of dollars are lost annually on underused clothes (A New Textiles Economy: Redesigning fashion's future, 2017), indicating the need to extend the lifespan of clothing, find appropriate business models to mitigate the trend set by fast fashion, and support responsible consumption.

A better understanding of the industry's challenges has led some fashion brands, designers, retailers, and consumers to start making socially responsible choices (Jacobs et al., 2018). Consequently, the term sustainable fashion has become widely discussed, with discussion extending beyond social responsibility toward long-term systemic, sustainable solutions that consider all life cycle stages of the fashion industry. A holistic understanding of sustainable fashion is complex - its production and consumption represent wicked problems (Rittel and Webber, 1973) that are interconnected, incomplete, contradictory, and where solutions are difficult to find. For example, if the amount of water or chemical dyes needed to produce a pair of jeans is reduced, how does it impact energy use or garment color? Transparency is needed to make 
appropriate, socially responsible decisions. Fashion brands are still reluctant to disclose this information fully (Chun et al., 2021). Gaps in consumers' understanding of life cycle stages and a lack of transparency have been identified as two of the most significant barriers to the discussion of systemic changes (e.g., toward circular economy) (Camacho-Otero, Boks and Pettersen, 2018) and diffusion of circular business models.

Millennials and the older segment of Generation Z (Gen MZ) are often seen as a leading force in transitions toward sustainable fashion. They are consistently increasing their awareness of the complexities of fashion production and consumption. Still, increasing awareness and transparency of fashion production does not necessarily translate into more sustainable actions and practices (Peirson-Smith and Evans, 2017; Turunen and Halme, 2021) when Gen MZ uses its substantial spending power (Moran, 2020). However, they have already changed the ways of advertising, sales, and information sharing by abandoning traditional media for Instagram, Facebook, YouTube, event sales, and other channels (Park, Ciampaglia and Ferrara, 2016; Stein, Spinler and Vanthournout, 2020). Gen MZ consumers use these channels (DeVaney, 2015; Serazio, 2015) to influence other age groups and promote new trends, consumption patterns, and lifestyles (Thelwall, 2021).

Recently, transition design (Escobar, 2018; Irwin, 2018) emerged as a design-led approach to tackling wicked problems and supporting transitions to more sustainable lifestyles. We use the transition design framework (Irwin, 2018) in this work to reflect on our mindset and values, theories that might support design for social change at scale, visions of sustainable fashion consumption, and new ways of designing (e.g., multi-stakeholder co-design, use of different design approaches). We used the framework previously to discuss a future-oriented service, Zygo, which aims to mitigate the consumption of durable goods among millennials by extending the lifespan of goods (Srivastava, 2017; Srivastava and Culén, 2018, 2019a, 2019b).

In this work, we describe two small qualitative studies that aim to gain insights into how Gen MZ consumers understand sustainable fashion and responsible consumption, in particular: 1) the complexity of the fashion industry's unsustainability 2) what it implies regarding sustainable fashion consumption 3) the opportunities that information and communication technologies (ICT) provide for creating supporting platforms, services, and business models that align with Gen MZ's visions, demands, and needs. The insights from these studies, and three other design projects that we supervised in the context of a larger funded project that sought to understand greener consumption more generally are then related to Zygo. This paper contributes to transition and interaction design by providing a perspective on how Norwegian Gen MZ understands sustainable fashion, the meaning of adopting sustainable practices related to clothing, and their thoughts on desirable services for the future that support their efforts to be responsible fashion consumers. Furthermore, we show how to extend Zygo to include local communities of practice concerned with fashion that offer sustainable services and business models toward responsible consumption and the continued, dynamic creation of sustainable fashion practices among Gen MZ consumers.

Next, we address some relevant literature and our previous work on sustainable consumption for Gen MZ and the digital solutions that were suggested. Then, we present our method, followed by the insights gained. Finally, we show how to integrate these insights with Zygo to provide services and business models for Gen MZ consumers.

\section{BACKGROUND}

This section is divided into four parts: 1) relevant work discussing consumers' mental model of sustainability and sustainable consumption, 2) designing for change, 3) Zygo, and 4) findings from the three small design projects that are related to the research described in this paper.

\subsection{Consumers' Mental Models of Sustainability and Sustainable Consumption}

Studies report that Gen MZ consumers increasingly make conscious and green choices (McDonald and Oates, 2006), showing a clear preference for brands that conduct their business with regard to environmental and social safety - in other words, products, services, and economies that could be described as being within the safe and just space for development (Rockström et al., 2009; Steffen et al., 2015; Raworth, 2017).

The mental concepts around sustainability and sustainable product attributes may differ between the fashion industry and consumers. Hanss and Böhm (2012) studied the latter (i.e., how Norwegian consumers 
understand sustainability and attributes of sustainable products). Their study found that consumers' general understanding of sustainability covered its five dimensions: environmental, social, economic, temporal, and developmental. Consumers focused on recyclable packaging, ecological production, fair payment for production, humane animal treatment, low energy use, and low carbon dioxide emissions during production and shipping. For the fashion industry specifically, the most important aspects of sustainability were fair and ethically made garments and accessories (e.g., no child labor, transparent production and fair pay (social and economic sustainability), sustainable production methods, and responsible waste management (environmental sustainability)).

Sustainable fashion practices are uniquely challenging because they extend beyond the utilitarian notion of fashion and into personal identity, need for distinction, status, and social acceptance (Niinimäki and Hassi, 2011). The novel practices and business opportunities suggested in the literature often have to do with upcycling, recycling, reconstruction, and zero waste (Khandual and Pradhan, 2019), or collaborative use and custom-made fashion, including Do-it-Yourself (DiY). De Angelis, Amatulli, and Pinato (2020) investigated differences in luxury and fast fashion consumption, concluding that luxury fashion brands activate a higher intention to purchase than sustainability associated with fast fashion brands. The authors attribute this to the intrinsic characteristics of luxury products: high quality, long life cycle, and limited quantities - all consistent with the consumers' ideas of sustainability. They argue further that these findings open for novel opportunities for both mass and luxury fashion. Previous research also shows that Gen MZ is open to new business models, such as sharing economies in luxury fashion consumption, as the study by Jain and Mishra (2020) finds.

Within sustainable interaction design, Pierce and Paulos (Pierce and Paulos, 2011) discussed consumption in terms of acquisition, possession, dispossession, and reacquisition. In particular, they paid attention to reacquisition, the use of secondhand goods, as a way to extend the lifetime of products and possibly lead to more sustainable consumption practices, especially when dispossession is linked to reacquisition. Another take-away from this work is related to the importance of designing for and with communities of reacquisition and that designing from communities of reacquisition generally works towards seeking and shaping radically different alternatives to the existing ones. In (Odom et al., 2009), the authors present an interesting perspective on the strength of attachments to products, linking it to the function of the product, its meaning, and materials, all influencing the length of the use of the product.

\subsection{Designing for Change}

Design and fashion designers are, in part, responsible for our (over)consumption, continuously persuading with new trends and aggressive marketing. They are also increasingly called upon to focus on values beyond profit and to work for the greater social good (Papanek, 1971; Chick and Micklethwaite, 2011; Niedderer, Clune and Ludden, 2017). To counter the challenges in the industry, several directions have been proposed, both through design and consumer behavior change, for example, slow fashion, behavior change (Becker-Leifhold, 2018; Brewer, 2019), or transition design (Kossoff, 2015; Irwin, 2018) - the latter approach chosen for this work because of its holistic perspective, which also looks into the design practice itself, theories that support design for change, values, and the ability to focus on the future by generating visions of preferred lifestyles.

The design practice used in our previous work that aimed to mitigate overconsumption among millennials (Srivastava and Culén, 2018) was based on integrated research through design (Zimmerman and Forlizzi, 2014) and service design, while the theory chosen to support the transition in most of the described design projects was social practice theory (Shove and Pantzar, 2005; Ingram, Shove and Watson, 2007; Kuijer, 2014). The main elements that configure practices (shown in Figure 3 within the context of the master's thesis project (Hilde, 2019)) whose re-combination leads to new practices, are material things (both digital and physical), skills (knowledge), and meanings (e.g., creating a more sustainable lifestyle).

\subsection{Zygo - Design Led Reframing of Secondhand Marketplaces}

Zygo is a future oriented, integrated service designed to reframe secondhand marketplace for millennials and Generation $\mathrm{Z}$ and propose an adequate business model, community building model, and privacy and safety (suggesting a membership-based model for participation). To design Zygo, in depth research on the lifestyle 
of young consumers (aged 16-27) was central (Srivastava and Culén, 2019a) to establishing pathways for the flow of goods between consumers in different life phases and with distinct consumption habits (Srivastava and Culén, 2019b). The service opened for the building of small local communities of practice, which might include repair, redesign, or upscaling. Importantly, Zygo was designed so that new community-based consumption practices could be shaped dynamically and continuously - a feature that we use in this work.

The evaluation of Zygo was carried in two separate workshops with four millennials and three experts (see Figure 1). The workshop with millennials confirmed that Zygo meets their lifestyles, while experts found that the concepts that Zygo embodied offered opportunities for future extensions and support sustainable practices.
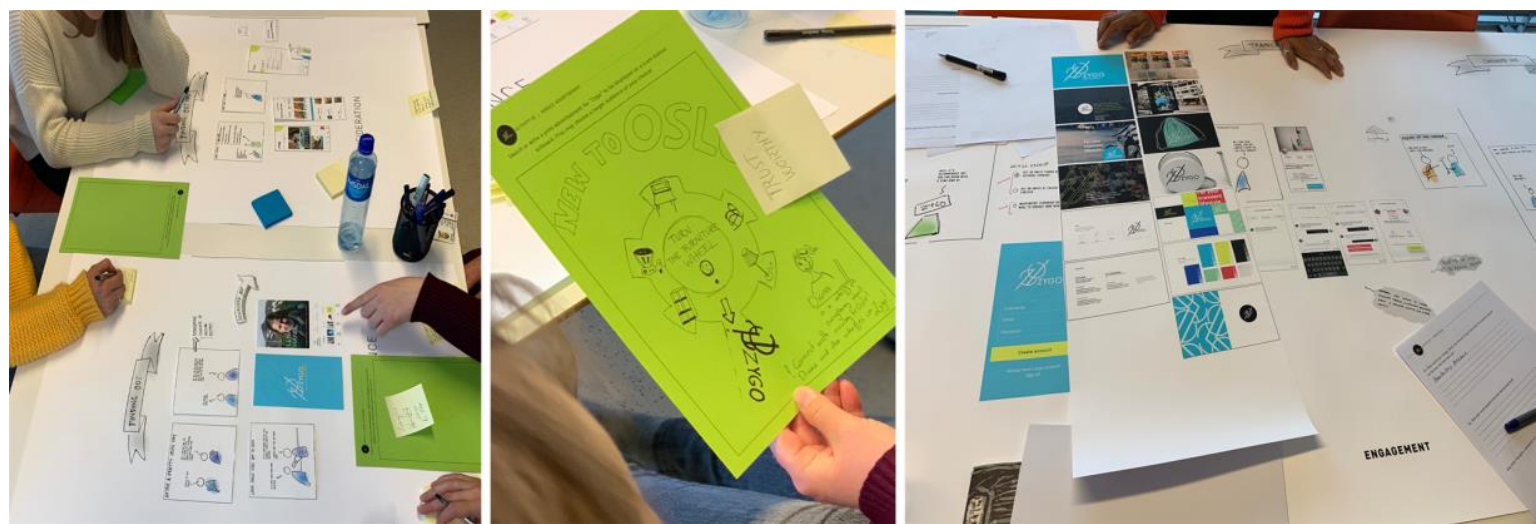

Figure 1. a) Evaluation of Zygo with millennials b) millennials making suggestions for new Zygo services c) the expert evaluation covered the service, branding, business model, strategies for community building. Photos: Culén

\subsection{Supervised Projects that Provided Insights used in this Research}

As mentioned, a large, funded research project served as an umbrella for several smaller design projects in the context of research-based teaching or supervision of master's thesis design projects with a focus on fashion consumption. We briefly present three projects and their main findings.

Conserve and Consume student project (Fosser et al., 2017) (a course project) engaged millennials in workshops and interviews to identify design opportunities. The first idea was an Interactive Wardrobe. By scanning the garments, one could find out which items were not used and nudged to resell garments that were not used over a certain amount of time, e.g., a year. During the Interactive Wardrobe prototype evaluation, the participants said that clothes were very personal. They felt attached to them and were not interested in selling or sharing their unused clothes. They liked the idea of using secondhand clothing but acting on it was different - only a few bought secondhand. They were more interested in being environmentally friendly and wanted garments with good production information.
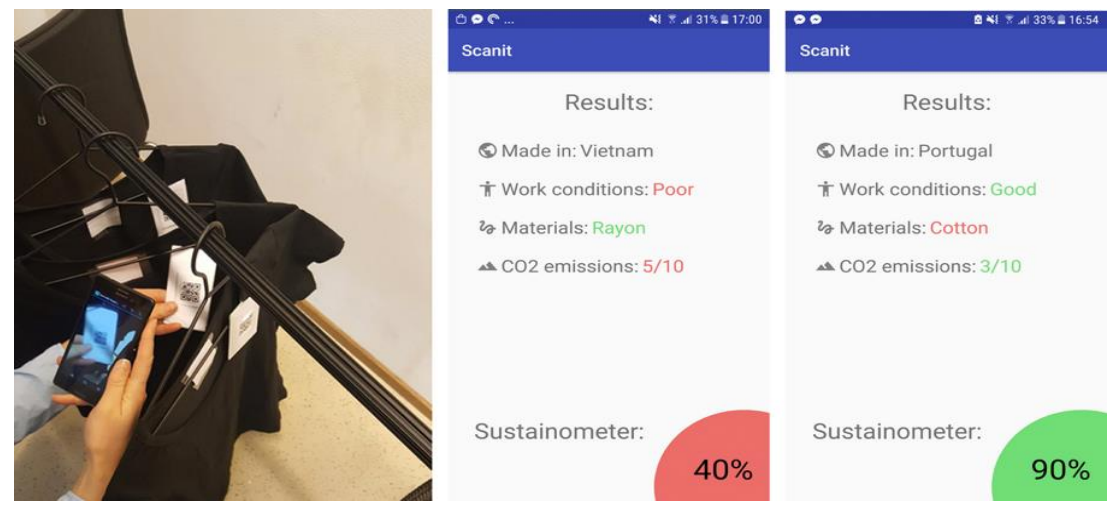

Figure 2. Scanning the tag of a t-shirt, to find out about the place of origin, work conditions, material, and $\mathrm{CO}_{2}$ emissions. The information was combined into a sustainability percentage (in the bottom right corner). Images: (Fosser et al., 2017) 
This led to the second prototype ScanIt (see Figure 2), based on making such information readily available. In the evaluation of ScanIt, the team focused on exploring how knowing this information could affect purchasing practices. Their explorations revealed that almost all participants would change their initial choices after finding out issues with garment production, particularly its environmental impact and materials. Many commented that it felt good to select fair-made and environmentally friendly products.

Transitions to more sustainable fashion (Hilde, 2019), a master's thesis project, looked into possibilities to connect consumers and fashion designers, different business model concepts for niche audiences. Hilde examined how new practices around fashion could be developed and how access might be given to consumers to the process of design and garment production. Hilde collaborated with a fashion designer, and they used woven QR codes that were sewn onto garments, linking the garment to a video showing how reconstruction (the use of old material to make an entirely new design) was implemented, how the item was priced, and other relevant production and material information (see Figure 3). Follow-up with consumers was possible.

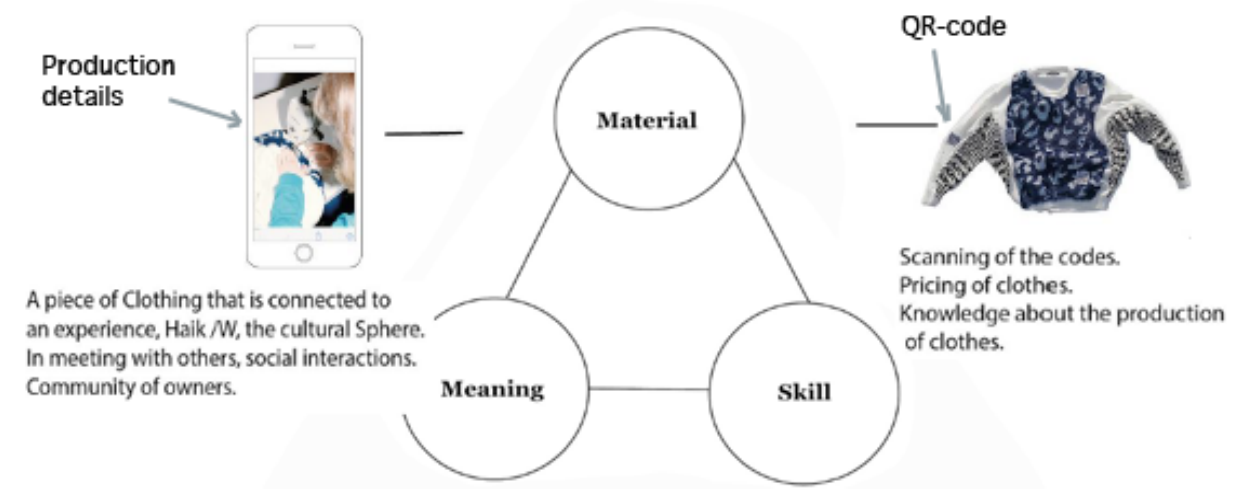

Figure 3. Adopted from (Hilde, 2019), showing how the sweater was made, scanning the woven QR-codes that are a part of the sweater. Sweaters are sold through events and a consumer could then interact with the designer

Scaffolding secondhand fashion consumption among adolescent girls (Fjeldstad and Leonardsen, 2017), was a master's thesis project. Fjeldstad and Leonardsen noted a lack of platforms targeting young girls (15-20) for secondhand fashion sharing. In the fashion-focused age, girls were more prone to sharing garments than older consumers. At that age, they experience occasions like confirmations, balls, and end of high school celebrations. Fjeldstad and Leonardsen designed and evaluated a service for this age group, aiming for the app design itself to be cool, use familiar interactions, and be simple, safe, and enjoyable to use.

\section{METHODS}

Two qualitative studies were carried out with Gen MZ participants (aged 19-35), an action research intervention, and an online, open questionnaire (instead of in-person interviews, which were not possible due to COVID-19). The study participants were selected based on their interest in sustainability, such as taking a transition design course to learn about the design of technologies within a safe and just space for the development of humanity (Rockström et al., 2009; Raworth, 2017). In contrast, Zygo and student projects that we supervised did not focus on participants' a priori stance favoring sustainable design, just on their age.

The action research intervention was chosen to observe actions rather than what participants say they would do regarding the acquisition of secondhand garments. The study had four participants, three of whom participated in person, while the fourth used video conferencing. Notes were taken. A room was arranged in one of the researcher's homes with clothing organized into three categories: giveaways (placed into large plastic bags), borrow/trade (one side of the wardrobe), and rent/buy (the other side of the wardrobe). Items were inspected for faults prior to the intervention. All clothes were medium in size, and the participants were chosen accordingly. Participants were chosen from among acquaintances of the person who provided clothing items for the study to mitigate hesitation about items of unknown origin. The items were a good mix of luxury, mid-range, and lower-end fashion brands in all three categories. As the participants walked into the room, the researcher explained the arrangement and asked them to talk aloud while they looked at different 
sections and items (see Figure 4). After they were done looking, they were asked a few questions about possible services and business models that they might want to use. The interventions took between 30 minutes and an hour, a shorter amount of time than expected.
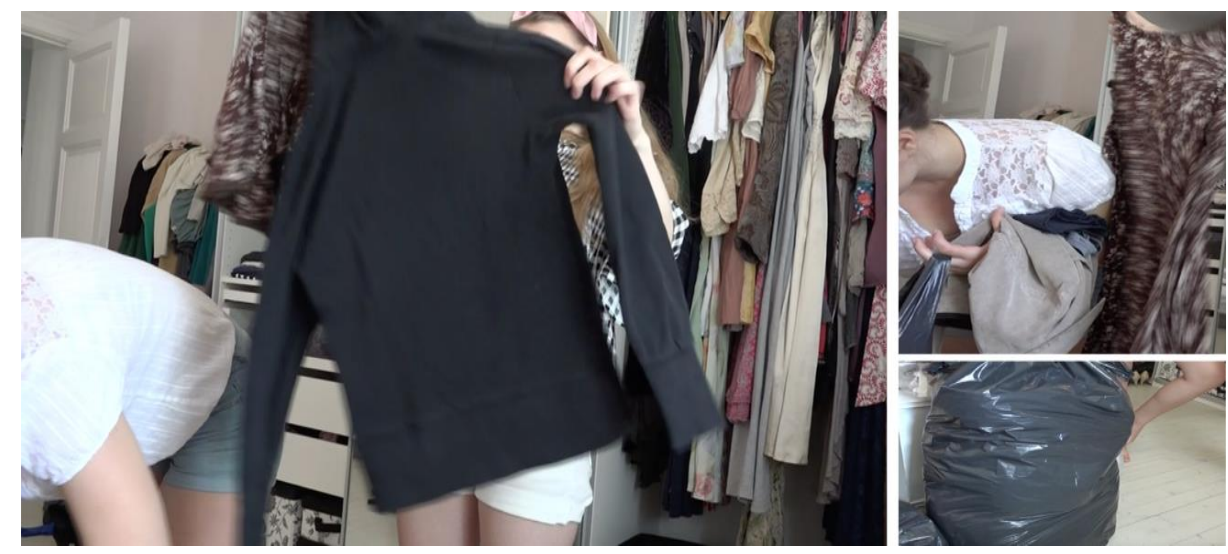

Figure 4. The images show the participants getting garments out of the bags containing free items. Photos: Culén

The online, open questionnaire had fourteen open-ended questions. It was implemented using Nettskjema, an online service that provides questionnaires. It was anonymous, and the answers to each question were randomized. The link to Nettskjema was sent to 25 people, and ten responses were received and analyzed using text analysis. The participants were students in a transition design course, design students, and a few others within the age group who we knew cared about the environment and social justice, but for whom we did not know anything about their attitude toward sustainable fashion.

The questions probed the thought process when buying a new piece of clothing, the length of use, how old the pieces were, and why they kept them. Further, we asked about dispossession practices, secondhand markets, and business models, such as luxury goods rental for special occasions. A range of questions addressed the importance of the material composition of garments and factors required for purchase (information on garment's production, identity, repair, or upcycling opportunities). Finally, we asked what participants considered the most interesting aspect related to sustainable fashion.

\section{INSIGHTS AND IMPLICATIONS FOR DESIGN}

This section has three parts: 1) insights from the action intervention, 2) insights from the questionnaire, and 3) implications for design, where we integrate the findings with Zygo toward sustainable fashion practices.

\subsection{Insights from the Action Intervention Study}

Being able to observe the body language of the participants while they engaged with clothing and talked through different choices while looking at or holding a particular garment was quite important. We, and the participants, could clearly relate our observations to the awareness/action gap that the literature addresses (Peirson-Smith and Evans, 2017; Turunen and Halme, 2021). For example, one participant, taking a cotton corduroy jacket out of a plastic bag with free items, said: "I would probably take this." The researcher pointed to some empty shopping bags and told the participant to take one and pack whatever she likes. "Ha? Hmmm. No, maybe not." Taking out the next item, a viscose dress (a more environmentally friendly material), she said: "Maybe this? No, this is not me." Neither the materials nor the brand status impacted her willingness to take a garment home - the participant chose nothing. When asked if anything would make any of the options more appealing, she replied in the negative: "Gosh! I have so much stuff myself." Another participant responded similarly, adding that thinking that someone does not want these free items does not help - it made her not want them either. Their way of being sustainable in this situation was to not take any clothes with them. 
One participant was happy with many free things and of the four participants, she spent the longest time selecting items. She filled the purses found inside the black plastic bags and added a couple of smaller shopping bags to take home: "This is great, I can give some of these to friends also, they look new. I love stuff like this and what turns out not to fit me, I have someone else to hand it down to." The video conferencing participant had a green brand preference. A few items that were of that brand were selected from giveaway bags. They were than shown to her and she decided if she wanted them or not.

Participants showed no interest in the shared consumption (borrowing, renting, or trading) of ordinary, everyday clothing. They were worried that garments could get accidentally ruined, or that picking up and returning items would be inconvenient: "If I think of borrowing, I think that things would be a hassle with returning and so on, so it is best to buy [own]." Knowing the person whose clothes were for rent/trade/borrow was, on the one hand, positive, but on the other hand, there were worries about social consequences - as part of a circle of friends, they were familiar with each other's clothing, and it would feel awkward unless done by all. Furthermore, participants were not sufficiently interested in buying secondhand clothes, consistent with the findings from the Conserve and Consume student project.

One apparent limitation of this study is the small number of participants. However, we felt that we did gain insights, especially on the awareness/action gap, and found the participants' actions consistent concerning all options except for giveaway clothing. As that category got depleted, we stopped the interventions - a different approach would be needed to understand the actions and use of such secondhand clothing.

\subsection{The Insights from the Questionnaire}

We analyzed the questionnaire answers by looking for the themes related to 1) the level of understanding of the unsustainability of the fashion industry and how it affected practices around acquisition and dispossession, 2) opportunities for creating sustainable practices, 3) what interested participants most with sustainable fashion.

On the first topic, our findings were similar to those of the Conserve and Consume project, (Hilde, 2019), or (McDonald and Oates, 2006). The participants were interested in better and more understandable production information and found that the transparency still needed improvement: "Ideally, I would like to think more about the production of clothing, but that always seems so abstract." Most of the participants said that they try to make sustainable choices consistently. That includes concern with materials, the country of origin, care instructions, durability, fair and green production. Nevertheless, they also said that due to the non-transparency of many brands, they could not be sure that their choices were actually sustainable. Furthermore, half of the participants said that the basis for deciding on a purchase was the real need for an item of clothing. These participants valued this way of thinking as their way of acting sustainably in everyday life. With only one exception, participants liked to donate their used clothes to secondhand stores; alternatively, they placed them in recycling bins for clothing. Most participants do not consider selling clothes using either digital or physical secondhand markets (only three said that they might try to sell nicer items). While using secondhand markets to dispossess, the participants did not find them equally interesting for purchasing. Only one person said that they preferred to buy secondhand. Some said that they like secondhand markets and think that they do represent a sustainable choice. Others saw them as a sort of treasure hunt, where one might find unique pieces though nothing could be expected - it was a matter of luck. Two participants were not excited about them: "Not something that excites me" and "I would consider visiting one." In conclusion, we see the need to focus both on alternative ways to prolong use-life of clothing, for example, by creating stronger attachments (Odom et al., 2009) and aim to move secondhand markets from niche to mainstream for Gen MZ consumers. As mentioned earlier, Zygo's aim was to fulfill the latter (Srivastava and Culén, 2019a).

As for the second topic, ideas related to possible alternative and more sustainable choices, such as luxury rentals, were met with some enthusiasm, although most participants said that they had not tried them. One shared their rental experience: "I've rented a tuxedo once, and that was okay. I had to go to the store and get fitted, and then return later to get the stuff, and then again to return it after the event. So, it is too much hassle to do it often." The thinking in favor of rentals included the fact that dresses for special occasions can be really expensive, and once the expense is incurred, one feels that the dress has to be worn on many occasions (unless, of course, the individual's resources are plentiful). On the other hand, rental shops offer a variety of choices that might fit the exact occasion for which they are rented. In the long term, the rental approach was seen as offering benefits of choice, quality, personal savings, and environmental benefits. 
Regarding sustainable practices like upcycling, restyling, or reconstructing, only two participants were not interested. About half tried upcycling and restyling, with mixed results. The skilled ones reported it as a very satisfying experience. The less skilled participants were open to learning. Thus, in line with (Khandual and Pradhan, 2019), supporting sustainable practices is worth pursuing beyond DiY - and, as mentioned, perhaps in the context of services such as Zygo.

As for the third topic, one participant took a systemic swipe:

"Define interesting! I think the entire fashion industry needs a major systemic overhaul, from the rate of change with fashion houses outputting a minimum of two collections a year to fast fashion existing at all. I'm curious to see what kind of model can be built that keeps fashion interesting without making it financially inaccessible to the working class on the one hand and destroying the environment on the other."

Another participant pointed to social media as the source of the bad mindset taking hold:

"I think the trend-cycle is very interesting. Lately, there has been a surge in people buying fast-fashion brands and doing 'hauls' on the internet (on sites like TikTok and brands like Shein) with super-trendy items. When people are commenting that it is very unsustainable to be using $500 \$$ on polyester clothing that's going to go out of style in a month, the buyers are excusing themselves by saying "there is no ethical consumption under capitalism" and that they cannot afford to buy more sustainably, even though they spend hundreds of dollars on cheap clothing. I think it is a really unhealthy mindset, and it is exaggerated by social media where you have to be trendy and appear cool."

Further, a couple of participants mentioned greenwashing and mistrust of green brands until the government makes regulatory decisions that such companies would be required to comply with. Several mentioned fast fashion as a problem, and some referred to slow fashion as a sustainable alternative. Someone made a distinction between style and trend, where style is accentuated as something that fits the personal identity, while the trend is something that everyone should follow. Thus, focusing on style is better (more sustainable) than following trends. One participant liked the emerging technologies, like the technology that makes it possible to extract fibers from used items and make new clothes with recycled fibers.

\subsection{Implications for Design}

Discussing what might work in terms of sustainable practices, in line with findings from (De Angelis, Amatulli and Pinato, 2020; Jain and Mishra, 2020), the participants thought that luxury rentals made sense economically, and services that would provide quality, age appropriate rentals were viewed favorably.

Many participants said that they would like to use secondhand clothes for DiY re-construction, or at least easy upcycling or restyling. Two participants in the intervention and several questionnaire participants acknowledged that the skills needed for this way of using secondhand clothing might be a barrier to doing it. Skills had to go beyond the ability to fix a missing button. Thus, workshops to gain or improve skills were seen as interesting. Engaging in such practices had a potential to increase the attachment (Odom et al., 2009) and extend the life-span of textiles while reducing the textile waste.

One intervention participant returned to the idea of trading. The participant described the situation when she opened her overfilled wardrobe and thought that she had nothing to wear. She related this to not paying enough attention to how new items fit with the rest, making it difficult to create desirable styles later. Thus, if someone had something that would fit with something she loved, she would be happy to trade to get that item: "Maybe even, an idea would be to make an app where a stylist would help people to select clothes from their own wardrobe that fit well together - sometimes the potential of this is missed."

Some of the ideas discussed could be reconceptualized as services and business models in the context of Zygo. For example, a local Gen MZ fashionista might give styling advice for a small fee. Alternatively, as the basis for trade, Zygo social media (which is safe as membership is required) might be used to post the selfie of a person in an item that is in want of matching items or cool accessories. Members could then respond with images of items they own and think would fit well with the posted garment. If a match is found, a favorable trade or sale might be initiated. Furthermore, a service where a sustainability-oriented stylist is invited to come home and reduce the size of the wardrobe, leaving only environmentally friendly items that match other items in the wardrobe (and suit the owner well, both in terms of the fit and style), would work well with Zygo. The Zygo community members would have a variety of options to engage with sustainable fashion practices. For example, one might start by reducing the wardrobe, where no longer needed items are further used for learning to upcycle, restyle, or reconstruct clothing through community-organized workshops. As the community members move through different life stages, their needs change. Finding patterns related to clothing use with such life stage changes can uncover new dispossession pathways (Pierce and Paulos, 2011) and allow new sustainable business models to emerge dynamically. 


\section{CONCLUSION}

Two small qualitative studies were implemented to explore the understanding of sustainable fashion among already sustainability aware Norwegian Gen MZ consumers. The studies show that there is still a lot of room to develop sustainable fashion practices, in particular when making purchasing or dispossession decisions, or obtaining information concerning the fashion production. However, this situation implies numerous opportunities for design of new services and business models. As an umbrella service, we have used our future-oriented service Zygo, which supports local communities that actively contribute to development of sustainable practices and dynamically open pathways between different services and members in different stages of life.

While these studies, in part, confirmed the findings from the literature, they also shed a new light on some of the ways these young consumers liked to engage with sustainable fashion, generating ideas for new services and business models that support their visions and aspirations toward sustainable practices related to fashion that include personal style (and not trends), high aesthetics, comfort, and proper fit - in items that they actually need. Gen MZ consumers are getting ready for more responsible fashion consumption.

\section{REFERENCES}

Becker-Leifhold, C. V. (2018) 'The role of values in collaborative fashion consumption - A critical investigation through the lenses of the theory of planned behavior', Journal of Cleaner Production, 199, pp. 781-791.

Brewer, M. K. (2019) 'Slow Fashion in a Fast Fashion World: Promoting Sustainability and Responsibility', Laws, 8(4), pp. 24.

Camacho-Otero, J., Boks, C. and Pettersen, I. N. (2018) 'Consumption in the circular economy: A literature review', Sustainability, 10(8), pp. 2758.

Chick, A. and Micklethwaite, P. (2011) Design for Sustainable Change: How Design and Designers Can Drive the Sustainability Agenda. AVA Publishing.

Chun, E. et al. (2021) 'Business transparency and willingness to act environmentally conscious behavior: Applying the sustainable fashion evaluation system "Higg Index"', Journal of Global Scholars of Marketing Science, pp. 1-16.

Circular Fashion - A New Textiles Economy: Redesigning fashion's future (2017). Available at: https://www.ellenmac arthurfoundation.org/publications/a-new-textiles-economy-redesigning-fashions-future (Accessed: 21 June 2021).

De Angelis, M., Amatulli, C. and Pinato, G. (2020) 'Sustainability in the Apparel Industry: The Role of Consumers' Fashion Consciousness', in Muthu, S. S. and Gardetti, M. A. (eds) Sustainability in the Textile and Apparel Industries: Consumerism and Fashion Sustainability. Cham: Springer International Publishing (Sustainable Textiles: Production, Processing, Manufacturing \& Chemistry), pp. 19-33. doi: 10.1007/978-3-030-38532-3_2.

DeVaney, S. A. (2015) 'Understanding the millennial generation.', Journal of financial service professionals, 69(6).

Environmental indicator report - European Environment Agency (2014). Available at: https://www.eea.europa.eu/ publications/environmental-indicator-report-2014 (Accessed: 28 April 2021).

Escobar, A. (2018) Designs for the Pluriverse: Radical Interdependence, Autonomy, and the Making of Worlds. Durham: Duke University Press Books.

Fjeldstad, V. and Leonardsen, M. R. (2017) Scaffolding secondhand fashion consumption among adolescent girls-Cool and sustainable app design for better user experience of redistribution of clothing. Master's Thesis. University of Oslo.

Fosser, M. et al. (2017) Conserve and Consume - INF2260 - Høst 2017 - Universitetet $i$ Oslo. Available at: https://www.uio. no/studier/emner/matnat/ifi/INF2260/h17/projects/conserve-and-consume/index.html (Accessed: 28 June 2021).

Hanss, D. and Böhm, G. (2012) 'Sustainability seen from the perspective of consumers: Sustainability seen from the perspective of consumers', International Journal of Consumer Studies, 36(6), pp. 678-687.

Hilde, M. (2019) Transitions to more sustainable fashion: relational, transparent, and community building. Master's Thesis. University of Oslo.

Ingram, J., Shove, E. and Watson, M. (2007) 'Products and Practices: Selected Concepts from Science and Technology Studies and from Social Theories of Consumption and Practice1', Design issues, 23(2), pp. 3-16.

Irwin, T. (2018) 'The Emerging Transition Design Approach', in DRS 2018. Design Research Society 2018: Catalyst, 3 , pp. 968-989. doi: 10.21606/drs.2018.210.

Jacobs, K. et al. (2018) 'Green thinking but thoughtless buying? An empirical extension of the value-attitude-behaviour hierarchy in sustainable clothing', Journal of Cleaner Production, 203, pp. 1155-1169.

Jain, S. and Mishra, S. (2020) 'Luxury fashion consumption in sharing economy: A study of Indian millennials', Journal of Global Fashion Marketing, 11(2), pp. 171-189. 
Khandual, A. and Pradhan, S. (2019) 'Fashion Brands and Consumers Approach Towards Sustainable Fashion', in Muthu, S. S. (ed.) Fast Fashion, Fashion Brands and Sustainable Consumption. Singapore: Springer (Textile Science and Clothing Technology), pp. 37-54.

Kossoff, G. (2015) 'Holism and the reconstitution of everyday life: a framework for transition to a sustainable society', Design Philosophy Papers, 13(1), pp. 25-38.

Kuijer, S. C. (2014) Implications of Social Practice Theory for Sustainable Design. Doctoral dissertation. Delft University. Available at: http://resolver.tudelft.nl/uuid:d1662dc5-9706-4bb5-933b-75704c72ba30 (Accessed: 30 June 2021).

McDonald, S. and Oates, C. J. (2006) 'Sustainability: Consumer Perceptions and Marketing Strategies', Business Strategy and the Environment, 15(3), pp. 157-170. doi: 10.1002/bse.524.

Moran, G. (2020) 'Gen Z and Millennials 2020 report', Drapers, 9 September. Available at: https://www. drapersonline.com/insight/drapers-bespoke/gen-Z-and-millennials-2020-report (Accessed: 28 April 2021).

Niedderer, K., Clune, S. and Ludden, G. (2017) Design for Behaviour Change: Theories and practices of designing for change. Routledge.

Niinimäki, K. et al. (2020) 'The environmental price of fast fashion', Nature Rev. Earth \&Environment, 1(4), pp. 189-200.

Niinimäki, K. and Hassi, L. (2011) 'Emerging design strategies in sustainable production and consumption of textiles and clothing', Journal of Cleaner Production, 19(16), pp. 1876-1883. doi: 10.1016/j.jclepro.2011.04.020.

Odom, W. et al. (2009) 'Understanding why we preserve some things and discard others in the context of interaction design', in Proceedings of the SIGCHI Conference on Human Factors in Computing Systems. New York, NY, USA: ACM (CHI '09), pp. 1053-1062. doi: 10.1145/1518701.1518862.

Papanek, V. (1971) Design for the Real World - Human Ecology and Social Change. First American Edition. Pantheon.

Park, J., Ciampaglia, G. L. and Ferrara, E. (2016) 'Style in the age of instagram: predicting success within the fashion industry using social media', in Proceedings of the 19th ACM Conference on computer-supported cooperative work \& social computing, pp. 64-73.

Peirson-Smith, A. and Evans, S. (2017) 'Fashioning Green Words and Eco Language: An examination of the user perception gap for fashion brands promoting sustainable practices', Fashion Practice, 9(3), pp. 373-397.

Pierce, J. and Paulos, E. (2011) 'Secondhand Interactions: Investigating Reacquisition and Dispossession Practices Around Domestic Objects', in Proceedings of the SIGCHI Conference on Human Factors in Computing Systems. New York, NY, USA: ACM (CHI '11), pp. 2385-2394. doi: 10.1145/1978942.1979291.

Raworth, K. (2017) Doughnut Economics: Seven Ways to Think Like a 21st-Century Economist. White River Junction, Vermont: Chelsea Green Publishing.

Rittel, H. W. J. and Webber, M. M. (1973) 'Dilemmas in a general theory of planning', Policy Sciences, 4(2), pp. $155-169$.

Rockström, J. et al. (2009) 'Planetary boundaries: exploring the safe operating space for humanity', Ecology and society, 14(2). doi: $10.5751 / \mathrm{ES}-03180-140232$.

Serazio, M. (2015) 'Selling (Digital) Millennials: The Social Construction and Technological Bias of a Consumer Generation', Television \& New Media, 16(7), pp. 599-615. doi: 10.1177/1527476413491015.

Shove, E. and Pantzar, M. (2005) 'Consumers, producers and practices: understanding the invention and reinvention of Nordic walking', Journal of consumer culture, 5(1), pp. 43-64.

Srivastava, S. (2017) 'ZYGO: Design led reframing of secondhand marketplaces', Nordes, 7(1).

Srivastava, S. and Culén, A. L. (2018) 'Transition-oriented Futuring: Integrated Design for Decreased Consumption amongst Millennials', in DRS 2018: Catalyst. DRS 2018, 3, pp. 927-940.

Srivastava, S. and Culén, A. L. (2019a) 'From Niche to Mainstream Transitions: Digital Secondhand Markets for Millennials', in Proceedings of the International Conference ICT, Society and Human Beings 2019. ICT 2019, IADIS Press, pp. 19-27. doi: 10.21606/drs.2018.210.

Srivastava, S. and Culén, A. L. (2019b) 'Implications for Transitions to Sustainable Consumption: Finding Millennials' Behavior Archetypes', in IASDR 2019: Design Revolutions, pp. 1-12.

Steffen, W. et al. (2015) 'Planetary boundaries: Guiding human development on a changing planet', Science, 347(6223), pp. 1259855

Stein, N., Spinler, S. and Vanthournout, H. (2020) 'Face-to-face communication as a tool to support secondhand fashion sales: a field experiment at Fashion Week in Berlin', Sustainability, 12(5), pp. 1758.

Thelwall, M. (2021) 'Lifestyle information from YouTube influencers: some consumption patterns', Journal of Documentation. doi: 10.1108/JD-02-2021-0033.

Turunen, L. L. M. and Halme, M. (2021) 'Communicating actionable sustainability information to consumers: The Shades of Green instrument for fashion', Journal of Cleaner Production, 297, pp. 126605. doi: 10.1016/j.jclepro.2021.126605.

Zimmerman, J. and Forlizzi, J. (2014) 'Research Through Design in HCI', in Olson, J. S. and Kellogg, W. A. (eds) Ways of Knowing in HCI. Springer New York, pp. 167-189. 